\section{Distortion of the Tropopause due to Meridional Movements in the Sub-Stratosphere}

In the neighbourhood of the equator, the hejght of the tropopause is about $17 \mathrm{gkm}$. and at latitude $70^{\circ} \mathrm{N}$. about $10 \mathrm{gkm}$. The rate at which the height of the tropopause changes with latitude is, however, not uniform, the change being very rapid between $45^{\circ}$ and $20^{\circ}$ in winter, and between $50^{\circ}$ and $30^{\circ}$ in summer. The ring of cold air which collects near the tropopause over tropical latitudes will tend to spread out with a slight downward component towards higher latitudes. To compensate this movement, we may expect that there will be at lower levels a movement towards lower latitudes.

At the latitude of Agra $\left(27^{\circ} \mathrm{N}\right.$.) in winter, the meridional variation of temperature is least at about $12 \mathrm{gkm}$., while at higher levels the temperature increases towards the pole and at lower levels towards the equator. The lower boundary of the spreading equatorial cold air will lie in the neighbourhood of $12 \mathrm{gkm}$. It is also known from pressure data that

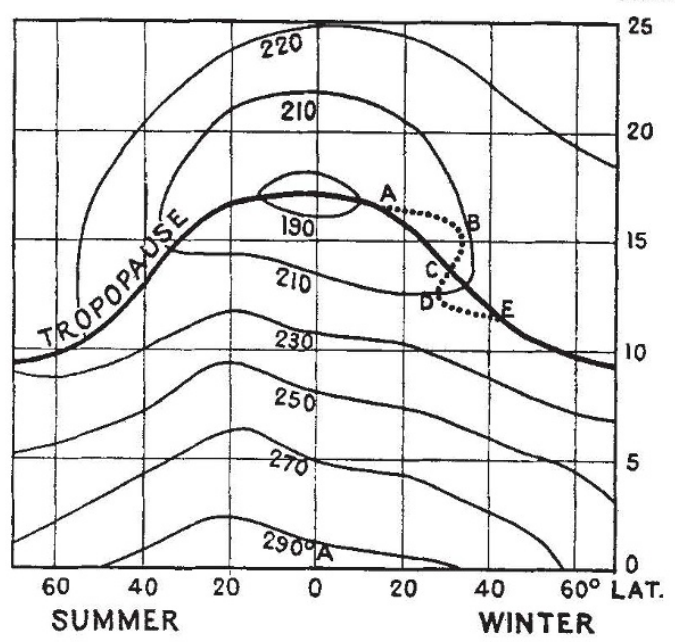

FIG. 1. Meridional distribution of temperature in the atmosphere over the northern hemikpliere showing the tropopause and its distortion.

the westerly winds of the season in sub-tropical latitudes have their maximum strength at a height of $10-12 \mathrm{~km}$. As an interesting consequence, it will follow that in the region of latitudes where there is a rapid variation of the height of the tropopause, it will often have a folded structure such as is repre. sented by the dotted line in Fig. 1.

At Agra, in winter, the type of tropopause which occurs most frequently is one in which the transition from the troposphere to the stratosphere occurs in two stages, the lower one being at a height of 12-13 gkm., with the lapse-rate suddenly changing from a high to a low value, often reaching zero above the transition, and the second transition at a height of about $17 \mathrm{gkm}$., this being invariably an inversion. Immediately below the upper inversion, there is frequently a layer of positive lapse-rate with a mean value of $5^{\circ} \mathrm{C}$. per $\mathrm{km}$. of about $2 \mathrm{~km}$. thickness.

This thermal structure is what one would expect if the lower transition corresponds to the tropopause of higher latitudes and the upper inversion transition to the tropopause of lower latitudes. Between these two, the air will be partly stratospheric air from higher latitudes and partly tropospheric air from lower latitudes. In summer, with the movement of the hump in the level of the tropopause towards higher latitudes, this folded structure of the tropo. pause is either absent at Agra, or if present, the difference of level between the transitions is very small.

At the latitude of Poona $\left(18^{\circ} \mathrm{N}\right.$.), the double transitions are much less conspicuous than at Agra, though one can often notice them in winter and early summer. When present, the difference of level between the two transitions is smaller than at Agra, the lower one being at a height of about $14 \mathrm{gkm}$. and the upper at 16-17 gkm.

On the other hand, many of the temperatureheight curves of places like Avalon (lat. $33^{\circ} \mathrm{N}$.), Groesbeck $\left(31^{\circ}\right.$ N.) and Fort Omaha $\left(41^{\circ}\right.$ N.) in the United States ${ }^{1}$ in summer show the double transition distinctly.

Meteorological Office,

K. R. Ramanathan.

K. P. RAMAKRISHNAN.

Poona.

Oct. 12.

1 Mon. Weather Rev., U.S.A., July 1914, May 1916, and June 1919 ; Bulletin, Mount Weather Observatory, 4, part 4, 1911.

\section{An Uitracentrifugal Study of Crystalline Pepsin}

WE have examined in the ultracentrifuge crystalline pepsin, prepared by a method closely resembling that of Northrop ${ }^{1}$, using both the velocity and the equilibrium methods ${ }^{2}$. The velocity method gave a sedimentation constant of $3.3 \times 10^{-13}$, as a mean of seven determinations having an estimated standard deviation of $0.15 \times 10^{-13}$. The equilibrium method gave a molecular weight of 35,500 as a mean of two determinations, the individual figures being 34,400 and 36,600 . Comparison of the molecular weight with the sedimentation constant shows that the molecule is spherical. Although, owing to the small number of determinations, these figures are only provisional, they lead to the same conclusion as Northrop's osmotic and diffusion data, namely, that as regards molecular weight and shape, Northrop's crystalline pepsin belongs to the same class of proteins as ovalbumin, Bence Jones protein and insulin. This conclusion is independent of whether the peptic activity is a property of the protein molecule or of an active group adsorbed on its surface.

The ultracentrifuge also yielded information as to the homogeneity of the preparations studied. The figures quoted above were obtained from preparations the absorption of which at 250-290 $\mathrm{m} \mu$ was almost entirely due to particles of a single size. Some wellcrystallised preparations, however, even after thorough washing, contained appreciable quantities of other particles, some slightly smaller than the main group and some so small as to be non-centri. fugible. The material with which we started (Parke. Davis pepsin $1: 10,000$ ) contained much of both types of impurity. This disappeared to a large extent in the first stage of purification (precipitation with magnesium sulphate) as was shown by the rise in the mean value of the sedimentation constant of the centrifugible part from $1.7 \times 10^{13}$ to $2.5 \times 10^{-13}$, by the decrease in the non-centrifugible part and by the increase in sharpness of the sedimentation boundary. Using these criteria, it was found that 